\title{
Plant pathogen infection risk tracks global crop yields under climate change
}

2 Thomas M. Chaloner ${ }^{1}$, Sarah J. Gurr ${ }^{1,2}$ and Daniel P. Bebber ${ }^{1 *}$

$3 \quad{ }^{1}$ Department of Biosciences, University of Exeter, Exeter, EX4 4QD, UK

$4 \quad{ }^{2}$ Department of Biosciences, Utrecht University, Paduallaan 8, Netherlands.

$5 \quad *$ Correspondence to d.bebber@exeter.ac.uk, tel. +44 1392725851

6 Authors ORCID numbers:

7 TMC 0000-0003-1655-0560

8 SJG 0000-0002-4821-0635

9 DPB 0000-0003-4440-1482

\section{Abstract}

11 Global food security is strongly determined by crop production. Climate change-induced losses to

12 production can occur directly, or indirectly, including via the distributions and impacts of plant

13 pathogens. However, the likely changes in pathogen pressure in relation to global crop production are

14 poorly understood. Here we show that temperature-dependent infection risk, $\mathrm{r}(T)$, for 80 fungal and

15 oomycete crop pathogens will track projected yield changes in 12 crops over the 21 st Century. For

16 most crops, both yields and $\mathrm{r}(T)$ are likely to increase at high latitudes. In contrast, while the tropics

17 will see little or no productivity gains, $\mathrm{r}(T)$ is also likely to decline. In addition, the USA, Europe and

18 China may experience major changes in pathogen assemblages. The benefits of yield gains may

19 therefore be tempered by the increased burden of crop protection due to increased and unfamiliar 20 pathogens. 


\section{Main text}

Plant pests and pathogens exert a major burden on crop production around the world ${ }^{1}$. The burden can be measured directly in yield losses or indirectly in the social, environmental and economic costs of control ${ }^{1}$. Like all species, crop pests and pathogens have particular tolerances to, or requirements for, particular environmental conditions ${ }^{2}$. These tolerances define their ecological niche, which determines the geographical regions and periods of the year that allow pests and pathogens to proliferate and attack crops ${ }^{2}$. As climate changes, suitable conditions for pest outbreaks shift in time and space, altering the threats that farmers face and the management regimes required for their control ${ }^{3}$. Modelling the pattern and process of future changes in pest and pathogen burdens is therefore a key component in maintaining future food security ${ }^{4}$.

Latitudinal range shifts of pests and pathogens are expected as the planet warms and populations track their preferred temperature zones ${ }^{3}$. Spatial movements in geographical distributions and temporal shifts in phenologies of wild populations are among the clearest signs of anthropogenic global warming ${ }^{5}$. Though distribution data for crop pests and pathogens are noisy and incomplete ${ }^{4}$, similar changes have been detected for hundreds a species of pests and pathogens over recent decades ${ }^{6}$. Increasing burdens of insect pests at high latitudes, and decreasing burdens at low latitudes, have been projected using ecological niche models (ENM) ${ }^{7}$. ENMs attempt to reconstruct the environmental tolerances of species from contemporary climates within the observed species range using statistical models ${ }^{8}$. Alternatively, species' responses to microclimate can be directly measured, and these responses incorporated into physiologically-based models of species performance ${ }^{9}$. Such mechanistic models are commonly used to project future crop yields ${ }^{10}$, and models have also been developed for some plant diseases ${ }^{11,12}$. However, we know little about how plant disease pressure is likely to change in future, nor how these changes will relate to crop yield responses to climate change.

Infection and disease are determined by complex and species-specific interactions between various biotic and abiotic factors ${ }^{1}$. Temperature is a major determinant of disease risk ${ }^{2,13}$ and global distributions of plant pathogens have shifted in line with historical global warming ${ }^{6}$. Here, we analyse temperature response functions for host infection for a suite of fungal and oomycete plant pathogens. We model the likely global shifts in temperature-dependent infection risk for the $21^{\text {st }}$ Century and compare climate-driven changes in this risk with projected changes in crop yields.

\section{Projected crop yield changes}

We compared current (2011-2030 mean) and future (2061-2080 mean) yields projections from three crop models (LPJmL, GEPIC, PEPIC) employing four GCMs (GFDL-ESM2M, HADGEM2-ES, IPSL-CM5A-LR, MIROC5) under the RCP6.0 representative concentration pathway. Carbon dioxide 
fertilization effects were included, and we compared projections with and without irrigation. Crop models do not explicitly consider the impacts of pests, pathogens and weeds on production. The major commodity crops of maize, wheat, soybean and rice are considered in all three crop models.

Crop models project greater yield increases at higher latitudes, with smaller increases or yield declines at low latitudes ${ }^{14,15}$ (Fig. S1-S4). Under the no irrigation scenario, GEPIC/PEPIC project substantial maize yield declines in Central and Latin America except for Argentina, and across Africa and northern Australia. LPJmL projects no such yield declines. Wheat yields also increase at high latitudes in all three crop models, with smaller increases at low latitudes in LPJmL and declines in GEPIC/PEPIC. North America and parts of Eurasia show the largest wheat yield increases, while GEPIC projects large declines in yield across the tropics. A similar latitudinal trend is projected for soybean but with little decline in the tropics. Soybean yield increases are projected across Eurasia in all models, and also Argentina and South Africa in GEPIC/PEPIC. The latitudinal gradient is less pronounced for rice, with the MIROC5 climate model suggesting a large increase in yield in the Southern hemisphere.

Eight further temperate and tropical annual crops are considered in LPJmL. In the unirrigated scenario, cassava yields increase under all four GCMs within $40^{\circ}$ of latitude, driven by large increases in India. However, all four GCMS suggest a smaller increase within $10^{\circ} \mathrm{N}$, caused by a yield decline in northern Brazil. Peanut, pea, rapeseed, sugarbeet, and sunflower show increases at all latitudes, with the largest increases at higher latitudes. Millet also shows increases at high latitudes, but yield declines at low latitudes. There are no consistent differences among the four GCMs for any of the crops. Results for sugarcane are more variable. Mean yield change projections suggest declines in Brazil and other Latin American countries, and in Southeast Asia, but an increase in the USA and in East Africa. Previous analyses based on the more extreme RCP 8.5 scenario similar yield increases with latitude latitudes, but more severe declines for some crops at low latitudes ${ }^{15}$.

Total projected crop production change is difficult to estimate because the spatial distributions of planted areas are impossible to predict, due to the influence of socioeconomic and cultural factors on planting choice. However, if production is calculated from projected yield changes on an estimate of current crop production, increases in production are expected for many crops (Fig. S5). Global wheat, cassava, rapeseed and sunflower production are predicted to increase by all models. LPJmL, and two climate models driving GEPIC/PEPIC, predict increases for rice. All models except HADGEM2-ES predict global soybean production increases (see Methods for analysis of soybean production). None of the crop models unequivocally project declines in production for any crop. In summary, crop models project global production increases driven primarily by yield increases at high latitudes, even without changes in cropping patterns to match shifts in areas likely to be most productive. 
Projected changes in yield for full irrigation are qualitatively and quantitatively similar to those for no irrigation across latitudes (Fig. S6). PEPIC shows substantially greater yield increases in the southern hemisphere for several crops. In certain cases, yields decline more at lower latitudes with full irrigation than with no irrigation. This is because irrigation enables cultivation in otherwise-unsuitable land for these crops, in these models. In summary, both irrigated and unirrigated crop model projections suggest positive latitudinal shifts crop yields over the next half century ${ }^{14,15}$.

\section{Projected infection risk changes}

Could these yield increases be offset by changing crop disease risk? Infection of plants by pathogens occurs at different rates dependent upon temperature, and each pathogen has a different optimum temperature at which infection of the host is most rapid ${ }^{2}$. Infection rates are commonly estimated by quantifying the appearance of disease lesions on host plants under controlled conditions ${ }^{16}$. We estimated relative temperature-dependent infection rates, $\mathrm{r}(T)$, of 80 fungal and oomycete plant pathogens, for which minimum $\left(T_{\min }\right)$, optimum $\left(T_{\mathrm{opt}}\right)$ and maximum $\left(T_{\max }\right)$ infection temperatures were available in the literature ${ }^{2}$ (Fig. 1, Table S1). These rates are relative (bound between zero and one) to enable comparison among pathogens. The rate is greatest, i.e. $\mathrm{r}(T)=1$, at $T_{\mathrm{opt}}$, and declines to zero as temperature decreases to $T_{\min }$ or increases to $T_{\max }$. We chose to model infection temperature responses rather than the more commonly-measured growth in culture, because in planta responses differ substantially from in vitro responses ${ }^{2}$. Essentially, the temperature range for infection is narrower, and optimum temperature lower, than for growth in culture. However, for two important pathogens, Magnaporthe oryzae (causing rice blast) and Zymoseptoria tritici (Septoria tritici blotch of wheat), infection temperatures were not available therefore we used lesion development and growth in culture temperatures, respectively. Optimum infection temperatures varied from 10.5 to $34.7^{\circ} \mathrm{C}$ among species (median 21.9, IQR 19.6 - 25.0). As global temperatures rise (Fig. S7), infection risks (and distributions) of these pathogens should shift latitudinally ${ }^{3}$.

Defining pathogen species richness, $\mathrm{R}_{\mathrm{r}}$, as the number of pathogens with $\mathrm{r}(T) \geq 0.5$ for their hosts in a particular location (Figs. S8, S9) at a particular time, we found that $\mathrm{R}_{\mathrm{r}}$ decreases at low latitudes, and increases at high latitudes, by the end of the $21^{\text {st }}$ Century under RCP 6.0 (Fig. 2a,b). $R_{r}$ increases substantially in Europe and China, but declines in Brazil, sub-Saharan Africa, India and Southeast Asia. Rapid global dissemination by international trade and transport ${ }^{17}$ means that pathogens are likely to reach all suitable areas that are not yet affected (Fig. S10).

In our model $\mathrm{R}_{\mathrm{r}}$ was projected to vary through the year, with the largest increases in North America, Europe and China during northern-Hemisphere autumn (Figs. 3, S11). Decreases in $\mathrm{R}_{\mathrm{r}}$ are projected at low to mid latitudes in northern-Hemisphere winter, shifting northwards into higher latitudes during summer. India is expected to see large declines in $R_{r}$ over much of the year, with increases in northern 
parts of India only in winter. Under increasingly strong greenhouse gas emissions scenarios, the overall latitudinal patterns of $\mathrm{R}_{\mathrm{r}}$ and resultant compositional change in both Hemispheres remain the same, but their amplitudes increase (Fig. 4). $\mathrm{R}_{\mathrm{r}}$ declined at low latitudes and increased at high latitudes, while compositional changes peaks at around $10^{\circ}$ and $30-40^{\circ}$.

Future changes in pathogen $\mathrm{r}(T)$ follow changes in yield by latitude for the majority of crops (Fig. 5). The majority of rice pathogens in our sample show increased $\mathrm{r}(T)$ across all latitudes, with few showing a widespread decline in the tropics. While $\mathrm{r}(T)$ of several maize pathogens is expected to increase at low latitudes, the risk from many others will decline. Maize, millet and sugarcane are expected to undergo yield declines at low latitudes, but these will be accompanied by declines in $\mathrm{r}(T)$ from many of their pathogens. Soybean, sunflower and wheat show little yield gain in the tropics, while experiencing reduced $\mathrm{r}(T)$ from a number of pathogens. Conversely, both yields and $\mathrm{r}(T)$ increase strongly with latitude. Cassava $r(T)$ generally increases near the equator. Overall, high latitudes will see increasing potential crop yields while simultaneously facing a larger $\mathrm{r}(T)$ by fungal and oomycete pathogens.

We found significant direct spatial matching between future changes in $\mathrm{r}(T)$ and crop yields (Fig. $\mathrm{S} 12)$. Correlations between future changes in crop yields and $\mathrm{r}(T)$ for maize, soybean, sunflower, and wheat exceeded 0.4. Although a weak negative correlation was calculated for cassava $(r=-0.09)$, our analysis included far fewer pathogens for this crop, compared to other crops (Table S2). Future crop production, particularly for three major crops, will likely not only be affected directly by climate change, but also indirectly via shifts in plant pathogen distributions.

Changing climate will affect not only the number of pathogens able to infect crops, but also the compositions of pathogen assemblages (Figs. 2cd). Overall, the largest changes in pathogen species composition will occur at high latitudes in the northern Hemisphere, particularly in Europe, China and central to eastern USA. Large changes are also expected in the Sahel, but this region, like much of Brazil, India and southeast Asia, will see declines in overall $\mathrm{R}_{\mathrm{r}}$. Hence, the change in pathogen assemblage in these areas is unlikely to pose a major threat to production. Europe, China and Peru are highlighted as regions where both overall burden and species turnover are greatest. These regions will therefore experience the greatest number of emerging, i.e. novel, pathogen pressure. Through the year, two pulses of pathogen assemblage change are seen at high latitude in the northern Hemisphere, first around April, second around September (Fig. 3). The largest changes in species composition are expected in Spring and Autumn in northern USA and Canada, Europe, and northern China (Figs. 3, S13). The largest changes in the Sahel are seen during April and May, while the largest changes in India are seen during May and June. 
We compared our model predictions against current known pathogen distributions (Fig. S10, Table S3). Restricting predicted distributions by host distributions (EarthStat) improved overall model fit, reducing false positive rates (predicting pathogen presence in regions where the pathogen is currently not reported) and increasing true negative rates (predicting pathogen absence in regions where the pathogen is currently unreported). Like other species distributions models, we predicted areas of suitability and therefore potential distributions of species, and did not attempt to reconstruct observed distributions. Pathogens are spreading globally ${ }^{17}$, observational records suffer from under-reporting ${ }^{4}$ and dispersal limitation prevents species from occupying all possible suitable environments ${ }^{18}$. These factors all likely contributed to the high false positive rates $(0.47$, IQR $0.37-0.57)$ of our model. However, high false positives rates were more likely in countries with low per capita GDP (Fig. S10h), indicating an under-reporting bias in developing countries ${ }^{4}$. Importantly, our model did not erroneously confine potential pathogen distributions, as false negative rates (predicting pathogen absence in regions where the pathogen is currently reported) were very low $(0.01, \mathrm{IQR}: 0.01-0.03)$.

\section{Discussion}

170 Our analyses are limited by the availability of infection temperature responses in the published literature. These are not a random sample of all known fungal and oomycete plant pathogens. Given that the historical research focus on plant pathogens has been in developed countries at high latitudes ${ }^{19}$, our sample is biased towards pathogens which have evolved to infect hosts optimally in cooler climates (Fig. S14). However, our sample does include pathogens able to infect both tropical and temperate crops (Figs. S8, S9), hence this bias does not preclude conclusions being drawn for tropical pathogens.

Infection of a susceptible primary host is central to disease development, but other processes such as spore dispersal, overwintering and infection of any alternate hosts are also important in pathogen epidemiology. We have modelled infection only, in common with previous studies on climate change effects on plant pathogens ${ }^{11,20}$, under the assumption that inoculum will be present, either through long-distance dispersal or overwintering ${ }^{21}$.

We did not attempt to model intra-specific variation in temperature response functions, though such variation does exist ${ }^{22,23}$. However, analysis of historical pathogen distributions indicates that range shifts have occurred in line with expectation suggesting that temperature adaptation is slow in comparison with climate change ${ }^{6}$. We employed infection temperatures rather than the more commonly-measured growth in axenic culture ${ }^{2}$, for all but two pathogens which were included because of their importance in agriculture ${ }^{1}$. The distinction is important because growth in culture has a wider geographical range than models based upon infection dynamics. 
190 We only considered temperature as a determinant of infection rates. However, infection by many 191 fungal and oomycete plant pathogens is promoted by wet conditions ${ }^{24}$. Multi-model mean projections 192 to the end of the $21^{\text {st }}$ Century suggest that precipitation will increase significantly in boreal regions 193 and decrease significantly around the Mediterranean, with smaller and less certain changes elsewhere 194 even under a high-emissions scenario ${ }^{25}$. Thus, there appears to be no major change in hydrology that 195 would alter our overall conclusions on latitudinal shifts in pathogen burden. In addition, historical 196 shifts in species populations have largely been driven by global warming ${ }^{6}$. Relative humidity (RH) 197 declines may offset the impact of increased pathogen temperature suitability at higher latitudes, 198 particularly across Europe (Fig. S15). Increased plant infection across Europe has been predicted under future climate, where pathogen temperature tolerances and infection wetting period were 200 considered ${ }^{11}$. RH was not considered in our model due to paucity of data concerning pathogen $\mathrm{RH}$ relations, as well as large uncertainties over future global $\mathrm{RH}$ projections ${ }^{26}$. To investigate the consequences of omitting humidity effects on infection risk, we compared results of models utilizing 3-hourly temperature and leaf wetness estimates with those utilizing only 3-hourly temperature and only monthly temperature during the growing season, for two rust pathogens (see Appendix in Supplementary Information). We found that that the monthly temperature models replicated the overall spatiotemporal patterns seen in the 3-hourly temperature and leaf wetness models, and that infection rate estimates were highly correlated among models. Finally, global observations ${ }^{27}$ and field-scale experiments ${ }^{28}$ suggest that temperature is the most important determinant of fungal distributions and activity.

210 We did not include potential future changes in crop phenology. Warming is expected to extend the 211 growing season of temperate crops by a few days by the end of the $21^{\text {st }}$ Century, while increasing 212 temperatures may reduce the length of the growing season in tropical crops ${ }^{29}$. As our seasonal 213 modelling was conducted using monthly crop calendars, the influence of altered growing seasons on 214 our results is likely to be small. We did not include potential future changes in crop distributions. The 215 socioeconomic factors leading to changes in future crop distributions are challenging to predict ${ }^{30}$, and 216 differing future land use scenarios are beyond the scope of the present analysis. The crop yield 217 projections we employed are subject to uncertainty, both due to the parameterization of the crop 218 models themselves and to the future climate change scenarios ${ }^{31,32}$. However, the global pattern of 219 greater yield increases at higher latitudes is conserved across models, and accords with the latitudinal trends in temperature.

Future crop yields have been modelled using only plant physiological responses to abiotic conditions. We analysed pathogen temperature physiology to understand how indirect, biotic responses to climate change could impact production. We have shown that crop disease burdens could track crop responses, increasing at higher latitudes where climate change is projected to boost yields. 
Furthermore, the suite of crop diseases that farmers face in some of the world's most productive regions will change dramatically. Crop yield losses to pathogens depend on many factors beyond infection, like host resistance and crop protection ${ }^{1}$. Agriculture must therefore prepare accordingly if any potential benefits of climate change on crop yields are to be realized.

\section{Acknowledgments}

230 Funding: TMC is supported by a BBSRC SWBio DTP studentship BB/M009122/1. DB and SG are supported by BBSRC grant BB/N020847/1 and the Global Burden of Crop Loss project (Bill and

232 Melinda Gates Foundation). SG is supported by a CIFAR Fellowship "The Fungal Kingdon: Threats

233 and Opportunities".

\section{Author contributions}

235 DB and TC developed the concept, collated the data, conducted the analyses and prepared the figures.

236 DB wrote the manuscript with contributions from TC and SG.

\section{Competing interests statement}

238 The authors declare no competing interest.

\section{Data availability statement}

240 Fungal and oomycete cardinal temperature data are available in Dryad

241 (https://doi.org/10.5061/dryad.tqjq2bvw6) and from Magarey, R. D., Sutton, T. B., \& Thayer, C. L.

242 (2005). A Simple Generic Infection Model for Foliar Fungal Plant Pathogens. Phytopatholog 95(1),

243 92-100 https://doi.org/10.1094/PHYTO-95-0092. The annual crop yield projections data used in this

244 study the Inter-Sectoral Model Intercomparison Project (ISIMIP, https://www.isimip.org). Fungal and

245 oomycete host plant data and geographical distributions (the Plantwise database) were used under

246 license for the current study, and are available with permission from CABI, Wallingford, UK. The

247 FAOSTAT commodity list is available from http://www.fao.org. Global gridded climate data and

248 climate projections are available from WorldClim (https://www.worldclim.org). Global gridded crop

249 distribution data used in this study are available from EarthStat (https://www.earthstat.org) and

250 MIRCA2000 (https://www.uni-frankfurt.de/45218031/data_download). Fungal and oomycete names

251 and name disambiguation data were obtained from Species Fungorum

252 (http://www.speciesfungorum.org/) and MycoBank (http://www.mycobank.org/). Annual per capita

253 GDP at purchasing power parity (PPP) data were obtained from the World Bank

254 (https://data.worldbank.org/). CMIP5 single level monthly near surface RH data were obtained from the Climate Data Store (https://cds.climate.copernicus.eu). 
Administrative boundaries for maps were obtained from GADM (https://www.gadm.org). Coastal outlines were obtained from package rworldmap version 1.3-6 for $\mathrm{R}$ version 4.0.1.

\section{Code availability statement}

All analyses were conducted using existing functions for $\mathrm{R}$ version 4.0.1. No significant custom code was used. R code used for data manipulation is available from the corresponding author on reasonable request.

\section{References}

1. Fones, H. N. et al. Threats to global food security from emerging fungal and oomycete crop pathogens. Nature Food 1, 332-342 (2020).

2. Chaloner, T. M., Gurr, S. J. \& Bebber, D. P. Geometry and evolution of the ecological niche in plant-associated microbes. Nature Communications 11, 2955 (2020).

3. Bebber, D. P. Range-Expanding Pests and Pathogens in a Warming World. Annu. Rev. Phytopathol. 53, 335-356 (2015).

4. Bebber, D. P. et al. Many unreported crop pests and pathogens are probably already present. Global Change Biology 25, 2703-2713 (2019).

5. Parmesan, C. Ecological and evolutionary responses to recent climate change. Annual Review of Ecology \& Systematics 37, 637-669 (2006).

6. Bebber, D. P., Ramotowski, M. A. T. \& Gurr, S. J. Crop pests and pathogens move polewards in a warming world. Nature Clim. Change 3, 985-988 (2013).

7. Yan, Y., Wang, Y.-C., Feng, C.-C., Wan, P.-H. M. \& Chang, K. T.-T. Potential distributional changes of invasive crop pest species associated with global climate change. Applied Geography 82, 83-92 (2017).

8. Elith, J. \& Leathwick, J. R. Species Distribution Models: Ecological Explanation and Prediction Across Space and Time. Annual Review of Ecology, Evolution, and Systematics 40, 677-697 (2009).

9. Kearney, M. \& Porter, W. Mechanistic niche modelling: combining physiological and spatial data to predict species' ranges. Ecology Letters 12, 334-350 (2009). 
10. Bondeau, A. et al. Modelling the role of agriculture for the 20th century global terrestrial carbon balance. Global Change Biology 13, 679-706 (2007).

11. Bregaglio, S., Donatelli, M. \& Confalonieri, R. Fungal infections of rice, wheat, and grape in Europe in 2030-2050. Agron. Sustain. Dev. 33, 767-776 (2013).

12. Bebber, D. P. Climate change effects on Black Sigatoka disease of banana. Philosophical Transactions of the Royal Society B: Biological Sciences 374, 20180269 (2019).

13. Delgado-Baquerizo, M. et al. The proportion of soil-borne pathogens increases with warming at the global scale. Nature Climate Change 10, 550-554 (2020).

14. Ostberg, S., Schewe, J., Childers, K. \& Frieler, K. Changes in crop yields and their variability at different levels of global warming. Earth System Dynamics 9, 479-496 (2018).

15. Rosenzweig, C. et al. Assessing agricultural risks of climate change in the 21 st century in a global gridded crop model intercomparison. PNAS 111, 3268-3273 (2014).

16. Magarey, R. D., Sutton, T. B. \& Thayer, C. L. A Simple Generic Infection Model for Foliar Fungal Plant Pathogens. Phytopathology ${ }^{T M}$ 95, 92-100 (2005).

17. Bebber, D. P., Holmes, T. \& Gurr, S. J. The global spread of crop pests and pathogens. Glob. Ecol. Biogeogr. 23, 1398-1407 (2014).

18. Soberón, J. \& Nakamura, M. Niches and distributional areas: concepts, methods, and assumptions. Proceedings of the National Academy of Sciences 106, 19644-19650 (2009).

19. Bebber, D. P., Holmes, T., Smith, D. \& Gurr, S. J. Economic and physical determinants of the global distributions of crop pests and pathogens. New Phytol. 202, 901-910 (2014).

20. Sparks, A. H., Forbes, G. A., Hijmans, R. J. \& Garrett, K. A. Climate change may have limited effect on global risk of potato late blight. Glob Change Biol 20, 3621-3631 (2014).

21. Chen, X. M. Epidemiology and control of stripe rust [Puccinia striiformis f. sp. tritici] on wheat. Canadian Journal of Plant Pathology 27, 314-337 (2005).

22. Zhan, J. \& McDonald, B. A. Thermal adaptation in the fungal pathogen Mycosphaerella graminicola. Molecular Ecology 20, 1689-1701 (2011). 
23. Robin, C., Andanson, A., Saint-Jean, G., Fabreguettes, O. \& Dutech, C. What was old is new again: thermal adaptation within clonal lineages during range expansion in a fungal pathogen. Molecular Ecology 26, 1952-1963 (2017).

24. Rowlandson, T. et al. Reconsidering Leaf Wetness Duration Determination for Plant Disease Management. Plant Disease 99, 310-319 (2014).

25. IPCC. Climate Change 2013: The Physical Science Basis. Contribution of Working Group I to the Fifth Assessment Report of the Intergovernmental Panel on Climate Change. (Cambridge University Press, 2013).

26. Dunn, R. J. H., Willett, K. M., Ciavarella, A. \& Stott, P. A. Comparison of land surface humidity between observations and CMIP5 models. Earth System Dynamics 8, 719-747 (2017).

27. Větrovský, T. et al. A meta-analysis of global fungal distribution reveals climate-driven patterns. Nature Communications 10, 1-9 (2019).

28. Liu, X. et al. Warming affects foliar fungal diseases more than precipitation in a Tibetan alpine meadow. New Phytologist 221, 1574-1584 (2019).

29. IPCC. Climate Change 2014: Impacts, Adaptation, and Vulnerability. Part A: Global and Sectoral Aspects. Contribution of Working Group II to the Fifth Assessment Report of the Intergovernmental Panel on Climate Change. (Cambridge University Press, 2014).

30. Sohl, T. L., Wimberly, M. C., Radeloff, V. C., Theobald, D. M. \& Sleeter, B. M. Divergent projections of future land use in the United States arising from different models and scenarios. Ecological Modelling 337, 281-297 (2016).

31. Müller, C. et al. Exploring uncertainties in global crop yield projections in a large ensemble of crop models and CMIP5 and CMIP6 climate scenarios. Environ. Res. Lett. 16, 034040 (2021).

32. Folberth, C. et al. Parameterization-induced uncertainties and impacts of crop management harmonization in a global gridded crop model ensemble. PLOS ONE 14, e0221862 (2019). 
Methods

336 A workflow detailing data preparation, model construction, model validation against known pathogen

337 distributions, and RH considerations is presented in Fig. S16.

338 Crop yields

339 Annual crop yield projections from 2006-2099 were obtained from the Inter-Sectoral Model

340 Intercomparison Project (ISIMIP, www.isimip.org) in January 2020. The crop models were LPJmL ${ }^{10}$,

341 GEPIC $^{33}$ and PEPIC ${ }^{34}$. LPJmL simulates changes carbon and water cycles due to land use,

342 phenology, seasonal $\mathrm{CO}_{2}$ fluxes and crop production. GEPIC and PEPIC are derived from the EPIC

343 agricultural yield and water quality model ${ }^{35}$. In EPIC, potential crop yield is simulated from solar

344 radiation, crop parameters, leaf area index and harvest index (the economic yield per unit

345 aboveground biomass). Each of these crop models was driven by four global circulation models:

346 MIROC $5^{36}$, HadGEM2-ES ${ }^{37}$, GFDL-ESM2M ${ }^{38}$ and IPSL-CM5A-LR ${ }^{39}$. Annual crop yield

347 estimates under RCP 6.0, with $\mathrm{CO}_{2}$ fertilization effects, and both the 'no irrigation' and 'full

348 irrigation' scenarios, were obtained for all available crops at $0.5^{\circ}$ spatial resolution. Fertilizer

349 application rates are modelled at country scale in each model. Irrigation is modelled using estimates

350 of the area equipped for irrigation per grid cell. GEPIC/PEPIC modelled maize, rice, soybean and

351 wheat. LPJmL additionally included cassava, millet, pea, peanut, rapeseed, sugarbeet, sugarcane and

352 sunflower. Yield differences between the 2060 - 2080 mean and 2010 - 2030 mean were calculated

353 per grid cell.

354 Climate data

355 Global estimates of recent (1970 - 2000 average) and future (2061 - 2080 average) average monthly

356 temperature at 5 arc minute spatial resolution were obtained from the WorldClim database

357 (www.worldclim.org) [accessed 5/2019]. For future estimates, all global climate models (GCMs) of

358 Representative Concentration Pathways (RCP) 2.6, 4.5, 6.0 and 8.5 were obtained (Table S4)

359 [accessed 5/2019]. For each RCP-GCM combination, average future monthly temperature was

360 calculated as the mid-point of average maximum and minimum monthly temperature, as no average

361 estimates were available. For each RCP, average monthly temperature was calculated as the mean of

362 all GCMs for that RCP. 
364 Estimates of pathogen infection cardinal temperature were extracted from two sources ${ }^{16,40}$.

365 Collectively, only pathogens with at least one minimum $\left(T_{\min }\right)$, optimum $\left(T_{\mathrm{opt}}\right)$, and maximum $\left(T_{\max }\right)$ estimate for infection cardinal temperature were included. To aid matching of species between sources, pathogen species names reported in the latter were updated according to the Species Fungorum database (SFD) (www.speciesfungorum.org) [accessed 4/2020] (Table S5). If no information was available on the SFD, Mycobank (www.mycobank.org) was used as an alternative [accessed 4/2020]. Discovery and sanction author(s) of species were not provided in one source ${ }^{16}$, and are not considered here. Pathogen species names have previously been processed ${ }^{40}$ and so were not altered. Mean $T_{\min }, T_{\mathrm{opt}}$, and $T_{\max }$ infection cardinal temperature were calculated for each pathogen (hereafter referred to as the 'Pathogen dataset'). Pathogens with nonsensical cardinal temperatures (i.e. mean $T_{\text {opt }}>$ mean $T_{\max }$ ) were excluded from the analysis, as it was not possible to calculate temperature response functions for such pathogens. Magnaporthe oryzae and Zymoseptoria tritici are two of the most destructive pathogens of rice and wheat ${ }^{1}$, respectively, but infection temperature estimates are unavailable. We therefore included cardinal temperature for lesion development of $M$. oryzae $^{41}$, and average growth in culture cardinal temperatures for 18 strains of $Z$. tritici ${ }^{42}$. It was assumed that average cardinal temperature for each pathogen was identical across all hosts, for each respective pathogen.

The Plantwise database (CABI) [accessed 28/10/2013, by permission] was used to estimate host range of each pathogen in the Pathogen dataset. To improve matching of pathogen species names, some names were updated in the Plantwise database, according to the SFD or Mycobank [accessed 4/2020] (Table S7). We also used included host range information provided by ref. ${ }^{16}$. All plant-pathogen interaction records for hosts recorded in EarthStat (http://www.earthstat.org) and MIRCA2000 ${ }^{43}$ were extracted from the Plantwise database. To enable matching of host species, scientific names were assigned to plant hosts found in EarthStat and MIRCA2000 (Table S6). The FAOSTAT commodity list (http://www.fao.org) was used to aid this process. Pathogens absent from the extracted plantpathogen interaction dataset were excluded from the Pathogen dataset. Consequently, 80 pathogens were included in the Pathogen dataset and hence included in this study (Fig. 1, Table S1).

Two approaches were used to estimate global host distributions for each pathogen included in the Pathogen dataset. First, for 150 crops (including forage crops, Table S6), global estimates of average fractional proportion grid cell harvested ( 5 arc minute spatial resolution) were obtained from EarthStat $^{44}$ (http://www.earthstat.org). Crops that could not be clearly identified as species (e.g. "mixed grain") or contained a large number of different plant genera (e.g. "vegetables") were excluded. Most crops classified as "not elsewhere specified" (nes) were also excluded. For 150 crops, each crop map was converted to binary presence/absence. If grid cell harvest area fraction was $\geq$ 
0.00001 (equivalent to $0.1 \mathrm{~m}^{2} \mathrm{ha}^{-1}$ ), the host was estimated as present in that grid cell. If $<0.00001$, hosts were assumed absent. These values were chosen to ensure that crops were estimated as present in grid cells, even if average fractional proportion harvested were estimated as very small. This approach enabled estimation of global distribution for each crop in EarthStat. The Earthstat crop distribution dataset does not provide crop calendars (i.e. the months during which the crop is growing).

Second, for 22 crops (Table S6), global estimates of growing season periods (around the year 2000) were extracted from MIRCA2000 at 30 arc minute spatial resolution ${ }^{43}$, and resampled to 5 arc minute resolution using neighbour joining algorithm in package raster for $\mathrm{R}^{45}$. For each crop, rainfed and irrigated growing season estimates were combined. This provided global monthly estimates of global host presence (within growing season) and absence (outside of growing season), and hence monthly global distribution estimates, at 5 arc minute spatial resolution for 22 crops.

411 For each pathogen, global distributions for all recorded hosts were combined, and converted to binary

412 presence/absence. This provided a single potential geographical distribution of each pathogen, based on reported pathogen host range (Plantwise) and geographic host distributions (EarthStat or MIRCA2000) (Fig. S8, S9). For example, if a pathogen was recorded in the Plantwise database to successfully infect four hosts recorded in EarthStat, any grid cells that were estimated to contain $\geq 1$ of these hosts were converted to 1 (present), and grid cells that there were estimated to contain 0 hosts were converted to 0 (absent). This was done independently for host distributions estimated from

418 EarthStat and MIRCA2000, resulting in two alternative potential geographical distribution of each

419 pathogen. Where MIRCA2000 was utilised, fewer pathogens were included, due to fewer crop species. Further, where host range was estimated from MIRCA2000, the potential geographical range of a pathogen of estimated each month, due to host growing season (Fig. S9). Host ranges were assumed independent for each pathogen, i.e. competition between pathogens for particular hosts was assumed to not occur.

\section{Modelling pathogen temperature-dependent infection risk}

Relative temperature-dependent infection rates, $\mathrm{r}(T)$, were calculated by a beta function ${ }^{46}$ (Equation S1) for each pathogen (Fig. 1, Table S1), for all climate data detailed above. We defined pathogen species richness $\mathrm{R}_{\mathrm{r}}$ as the number of pathogens with $\mathrm{r}(T) \geq 0.5$, i.e. those pathogens with high predicted infection rates. $\mathrm{R}_{\mathrm{r}}$ acted as a summary metric of pathogen risk per grid cell. 
432 Pathogen presence (defined as $\mathrm{r}(T) \geq 0.5$ ) was calculated for recent average monthly temperature 433 estimates utilising two alternative approaches. In the 'temperature-only model', pathogens were not 434 restricted by host distributions. In the 'temperature+host model', pathogens were additionally restricted by host distributions estimated from EarthStat. In both model iterations, a summary potential global distribution of each pathogen was calculated, whereby if a pathogen was modelled as 'present' in a grid cell $(j)$ during any month $(i)$, then the pathogen was recorded as 'present' in that $438 \operatorname{grid} \operatorname{cell}(j)$.

439 Outputs from both model iterations were compared to observed records of pathogen presence at 440 country or state scale (hereafter collectively referred to as 'region', 396 regions total), from the CABI 441 Plantwise database. Pathogen names in this dataset were updated according to the SFD or Mycobank 442 [accessed 4/2020] to improve matching to the Pathogen dataset (Table S7). Discovery and sanction 443 author(s) of species were not provided in this dataset, and so were not considered here. Thirteen 444 pathogens (Alternaria cucumerina, Botrytis cinerea, Cercospora carotae, Didymella arachidicola, 445 Diplocarpon earlianum, Fusarium oxysporum f.sp. conglutinans, Fusarium roseum, Globisporangium 446 ultimum, Nothopassalora personata, Puccinia menthae, Septoria glycines, Stigmina carpophila, and 447 Wilsoniana occidentalis) were excluded from model validation, due to an apparent lack of 448 observational records.

449 Models were run at 5 arc minute resolution, whereas observed pathogen records were at regional scale 450 (Fig. S10a, c). Hence, model outputs were summed to regional scale (Fig. S10b, d). If a pathogen was 451 modelled as 'present' in any grid cell $(j)$ in a region, for any month $(i)$, the pathogen was modelled as 452 'present' at the regional scale. Gross domestic product based on purchasing power parity (GDP 453 (PPP)) and research output (number of publications) were obtained from the World Bank Data 454 website for 230 territories (data.worldbank.org) [accessed 11/2018]. For the temperature+host model, 455 for each pathogen, median GDP (PPP) and median research output were calculated for territories 456 where (1) both the temperature+host model estimated, and the Plantwise database recorded a 457 pathogen as present (true positive (Sensitivity)), and where (2) the temperature+host model estimated 458 a pathogen as present, but the Plantwise database recorded a pathogen as absent (false positive (Type 4591 error)). Data were compared by Welch's Two Sample two-tailed $t$-test. Where GDP (PPP) and 460 research output were recorded at country scale, but pathogen records were recorded at state scale, 461 states were assigned country-level GDP (PPP) and research output. 
We calculated $\mathrm{R}_{\mathrm{r}}$ for recent and future average monthly $(i)$ grid cell $(j)$ temperature $\left(T_{\{i, j\}}\right)$, utilising two alternative host-restriction approaches. First, pathogens were restricted by host distributions estimated from EarthStat, for each future climate scenarios (RCP 2.6, 4.5, 6.0, and 8.5). Second, pathogens were restricted by host distributions estimated from MIRCA2000, and RCP 6.0 was used to estimate future average monthly temperature. This allowed for comparison between host restriction method on model outputs of change in spatial patterns of $R_{r}$.

For each model, change in $R_{r}$ was calculated as $R_{r}$ under future climate conditions, minus $R_{r}$ under recent climate, for each grid cell $(j)$, for each month $(i)$. Within a grid cell, increases or decreases in $\mathrm{R}_{\mathrm{r}}$ do not reflect the change of species composition ${ }^{7}$. Therefore, for each model, a modified Jaccard $(J)$ index $(1-J)$ of community dissimilarity (pathogen turnover, Equation S2) ${ }^{7,47}$ was calculated to characterize the change in community composition in each grid cell $(j)$, for each month $(i)$. High pathogen turnover indicates high community dissimilarity or a large change in species composition.

$$
\text { Equation S2: } 1-J_{\{i, j\}}=1-\left(\frac{a_{\{i, j\}}}{a_{\{i, j\}}+b_{\{i, j\}}+c_{\{i, j\}}}\right)
$$

where $a$ is the number of pathogens common to a grid cell under recent and future climate, $b$ is the number of pathogens unique to a grid cell under recent climate, $c$ is the number of pathogens unique to a grid cell under future climate, $i$ is the month and $j$ is the grid cell. Pathogen turnover was defined as zero for grid cells with no pathogens under both recent and future climates.

For each pathogen of each crop included in MIRCA2000, change in $\operatorname{r}(T)$ between current and future climate (RCP 6.0) was calculated for each grid cell (j), for each month ( $i$ ) (Table S2 provides the number of pathogens included for each crop). Pathogens were restricted by crop distributions estimated from MIRCA2000 (see above). For this analysis, we used estimates from MIRCA2000 for pulses as a proxy for pea crop (Pisum sativum). For each crop-pathogen combination, mean change in $\mathrm{r}(T)$ was calculated for each latitude ( 5 arc minute resolution), and then aggregated to $5^{\circ}$ resolution for plotting using the aggregate function in package raster for $\mathrm{R}^{45}$ (Fig. 5).

We tested for evidence of spatial matching between projected changes in crop yield and pathogen $\mathrm{r}(T)$. For each crop, Pearson correlations $(r)$ and spatial cross-correlations $\left(r_{\mathrm{c}}\right)$ were calculated between overall mean change in crop yield and pathogen $\mathrm{r}(T)$, aggregated to $2^{\circ}$ resolution. In this case, compared overall mean change in $\mathrm{r}(T)$ for all months, for all pathogens with overall mean change in yield from all available models under the no irrigation scenario. Spatial cross-correlations were calculated using the package spatialEco for $\mathrm{R}^{48}$. An inverse power law transformation was performed to derive a spatial weights matrix in the analysis of each crop. 
496 Northern and southern latitudinal ranges for plant pests and pathogens were extracted from the CABI

497 Plantwise database. As previous, some pathogen names in this dataset were updated according to the

498 SFD or Mycobank [accessed 4/2020] to improve matching to the Pathogen dataset (Table S7) and 13

499 pathogens were excluded from the analysis, due to an apparent lack of observational records.

500 Pathogen names were not updated in this dataset if they were absent from the Pathogen dataset.

501 Northern and southern latitudinal ranges for pathogens included in the Pathogen dataset were

502 compared to that of all fungi and oomycetes pathogens for which latitudinal ranges were available.

Relative humidity considerations

504 Coupled Model Intercomparison Project 5 (CMIP5) single level monthly near surface RH data $505\left(0.125^{\circ}\right.$ to $5^{\circ}$ spatial resolution depending on model $)$ were extracted from the Climate Data Store 506 (https://cds.climate.copernicus.eu). Data from all available future (RCP 6.0, 2070) and corresponding recent (1985) model-ensemble combinations (see Table S8 for further details) were extracted from

508 NC files and converted to raster objects.

509 For each model-ensemble-month combination, change in RH was calculated as future RH minus recent RH. If a model had multiple ensembles, mean change for each month was calculated from all ensembles. All data were resampled to 5 arc minute resolution using bilinear algorithm in package raster for $\mathrm{R}$. Mean monthly change in $\mathrm{RH}$ was calculated from all model estimates to provide single monthly estimates. Grid cells that contained no hosts in the EarthStat database were excluded from the analysis. Hence, only grid cells included in analyses of $\mathrm{R}_{\mathrm{r}}$ and pathogen turnover were included. Grid cells were aggregated to $2^{\circ}$ spatial resolution to calculate Pearson correlations $(r)$ between change in RH and change in $\mathrm{R}_{\mathrm{r}}$ (RCP 6.0) for March, June, September, and December.

The Appendix (see Supplementary Information) compares $r(T)$ estimates from models using 3-hourly temperatures estimates constrained by leaf wetness, with results obtained using only monthly average temperatures unconstrained by leaf wetness. water productivity with high resolution on a global scale. Agricultural Systems 94, 478-493 (2007). for maize. Agricultural and Forest Meteorology 221, 164-175 (2016). 
35. Williams, J. R. \& Sharpley, A. N. EPIC - Erosion/Productivity Impact Calculator: 1. Model documentation. (1989).

36. Watanabe, M. et al. Improved Climate Simulation by MIROC5: Mean States, Variability, and Climate Sensitivity. J. Climate 23, 6312-6335 (2010).

37. Collins, W. J. et al. Development and evaluation of an Earth-System model - HadGEM2. Geoscientific Model Development 4, 1051-1075 (2011).

38. Dunne, J. P. et al. GFDL's ESM2 Global Coupled Climate-Carbon Earth System Models. Part I: Physical Formulation and Baseline Simulation Characteristics. J. Climate 25, 6646-6665 (2012).

39. Dufresne, J.-L. et al. Climate change projections using the IPSL-CM5 Earth System Model: from CMIP3 to CMIP5. Clim Dyn 40, 2123-2165 (2013).

40. Bebber, D. P., Chaloner, T. M. \& Gurr, S. J. Fungal and Oomycete cardinal temperatures (the Togashi dataset). 2424892 bytes (2020) doi:10.5061/DRYAD.TQJQ2BVW6.

41. Viswanath, K. et al. Simulation of leaf blast infection in tropical rice agro-ecology under climate change scenario. Climatic Change 142, 155-167 (2017).

42. Boixel, A.-L., Delestre, G., Legeay, J., Chelle, M. \& Suffert, F. Phenotyping Thermal Responses of Yeasts and Yeast-like Microorganisms at the Individual and Population Levels: Proof-ofConcept, Development and Application of an Experimental Framework to a Plant Pathogen. Microb Ecol 78, 42-56 (2019).

43. Portmann, F. T., Siebert, S. \& Döll, P. MIRCA2000 - Global monthly irrigated and rainfed crop areas around the year 2000: A new high-resolution data set for agricultural and hydrological modeling. Global Biogeochemical Cycles 24, 1-24 (2010).

44. Monfreda, C., Ramankutty, N. \& Foley, J. A. Farming the planet: 2. Geographic distribution of crop areas, yields, physiological types, and net primary production in the year 2000. Global Biogeochem. Cycles 22, GB1022 (2008).

45. Hijmans, R. J. et al. raster: Geographic Data Analysis and Modeling. (2020).

46. Yan, W. \& Hunt, L. A. An Equation for Modelling the Temperature Response of Plants using only the Cardinal Temperatures. Ann Bot 84, 607-614 (1999). 
bioRxiv preprint doi: https://doi.org/10.1101/2020.04.28.066233; this version posted July 24, 2021. The copyright holder for this preprint (which was not certified by peer review) is the author/funder. All rights reserved. No reuse allowed without permission.

Chaloner et al.

Crop pathogens and climate change

553 47. Wiens, J. A., Stralberg, D., Jongsomjit, D., Howell, C. A. \& Snyder, M. A. Niches, models, and $554 \quad$ climate change: Assessing the assumptions and uncertainties. PNAS 106, 19729-19736 (2009).

555 48. Chen, Y. A new methodology of spatial cross-correlation analysis. PLOS ONE 10, e 0126158

556 (2015).

557 
bioRxiv preprint doi: https://doi.org/10.1101/2020.04.28.066233; this version posted July 24, 2021. The copyright holder for this preprint (which was not certified by peer review) is the author/funder. All rights reserved. No reuse allowed without permission.

Chaloner et al.

Crop pathogens and climate change

\section{Figure Captions}
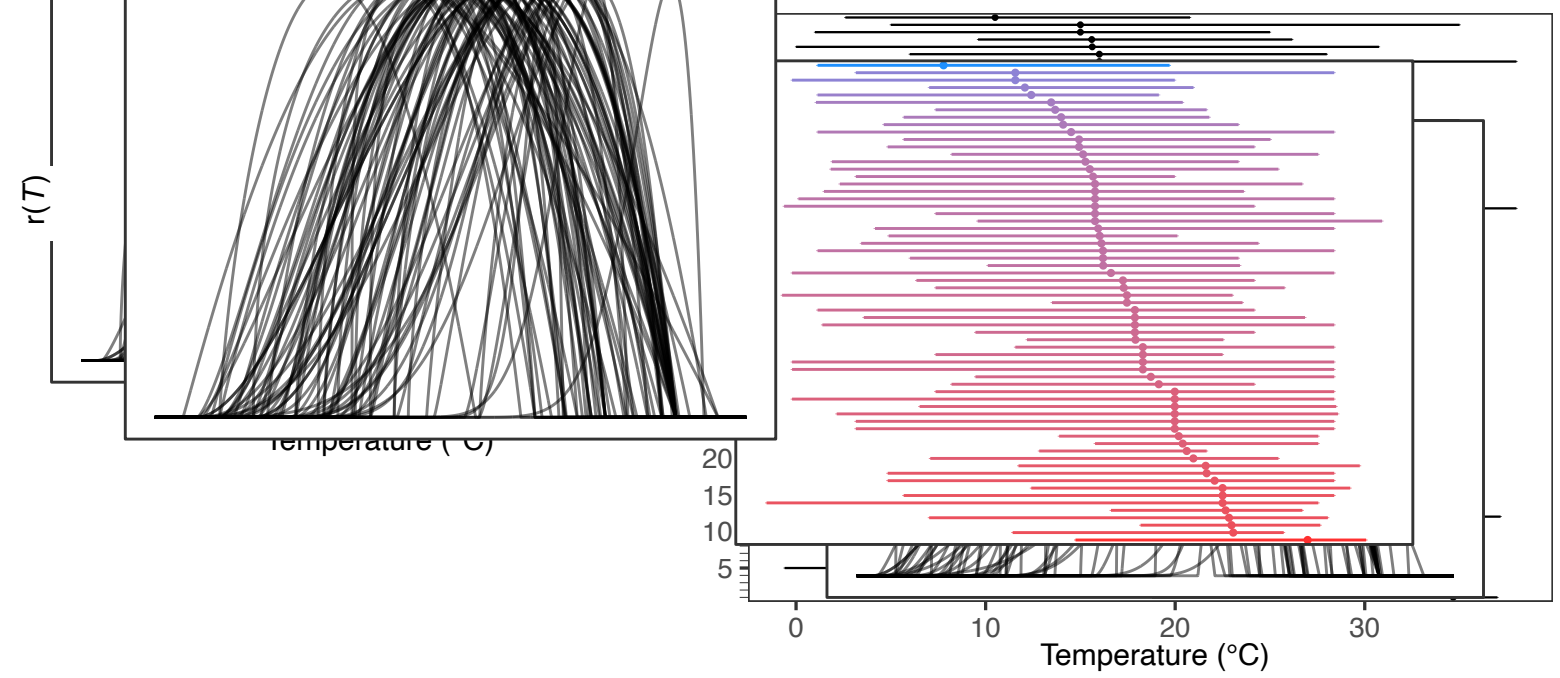

560 Fig 1. Summary infection cardinal temperature for 80 plant pathogens included in this study. (a)

561 Temperature response curves for $\mathrm{r}(T)$ determined by $T_{\min }, T_{\mathrm{opt}}$, and $T_{\max }$, as well as Equation $\mathrm{S} 1$.

562 Arrow indicates temperatures where $\mathrm{r}(T)=0.5$ for an example pathogen. (b) Points refer to $T_{\mathrm{opt}}$, bars

563 refer to temperature range (defined by $T_{\min }$ and $T_{\max }$ ). Pathogens are ordered by $T_{\mathrm{opt}}$. Pathogen ID in

564 Table S1.
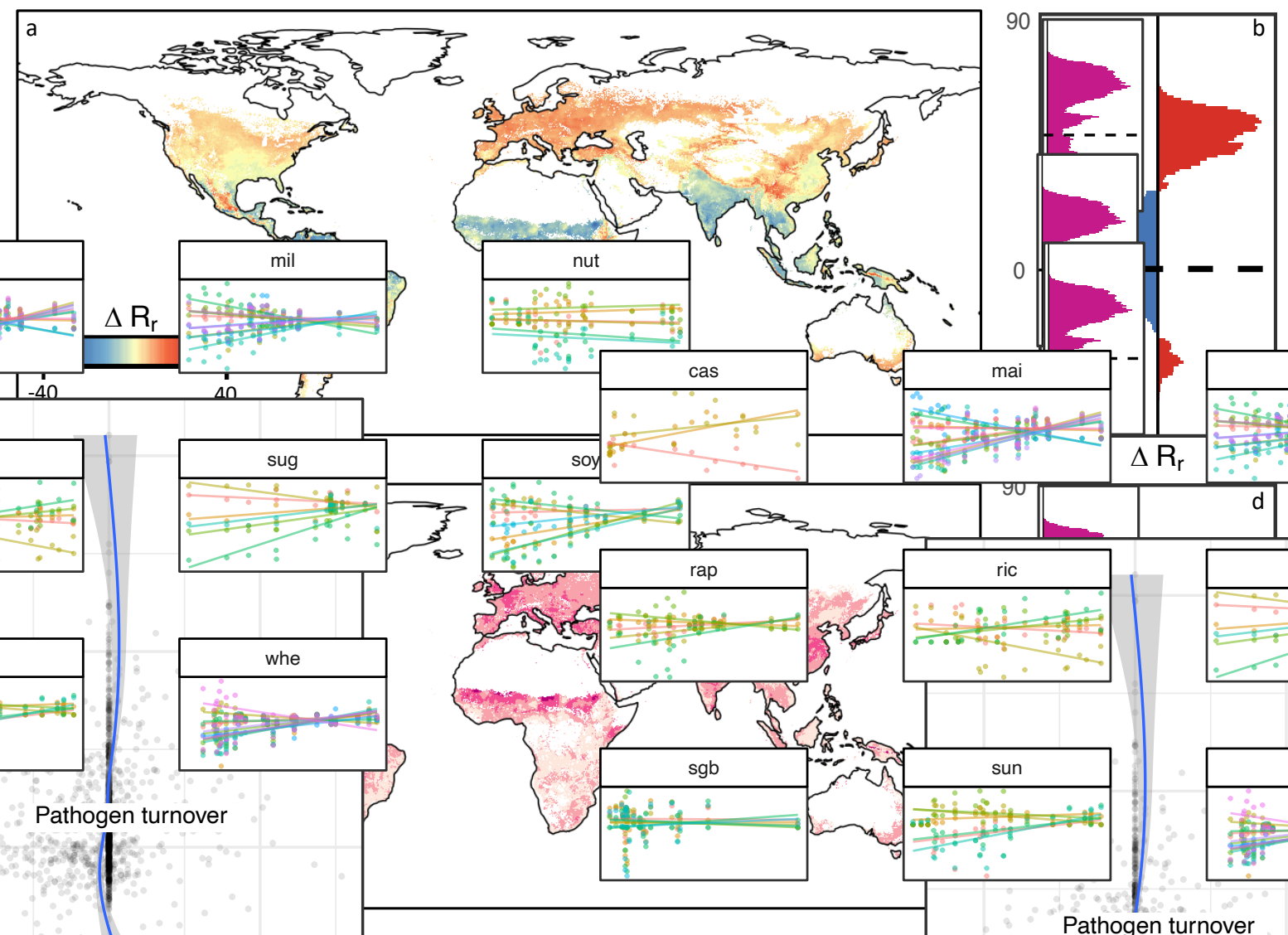
bioRxiv preprint doi: https://doi.org/10.1101/2020.04.28.066233; this version posted July 24, 2021. The copyright holder for this preprint (which was not certified by peer review) is the author/funder. All rights reserved. No reuse allowed without permission.

Chaloner et al.

Fig 2. Average change in $(a, b) R_{r}$ and $(c, d)$ pathogen turnover under RCP 6.0 across all months. Red and blue indicate increases and decreases in $\mathrm{R}_{\mathrm{r}}$, respectively. Darker pink indicates larger changes in pathogen turnover. Pathogens restricted by host distributions extracted from EarthStat. White grid cells contain no hosts and were excluded from the analysis. $(\mathrm{b}, \mathrm{d})$ Data aggregated to $1^{\circ}$ resolution for plotting.

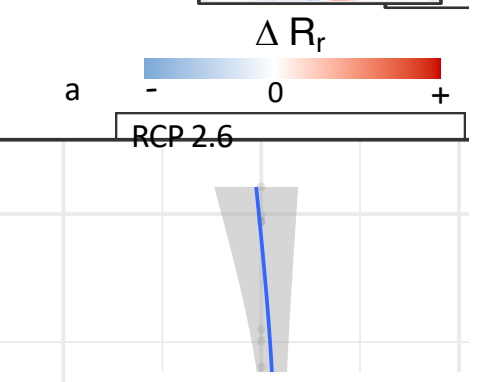

\section{Pathogen turnover}
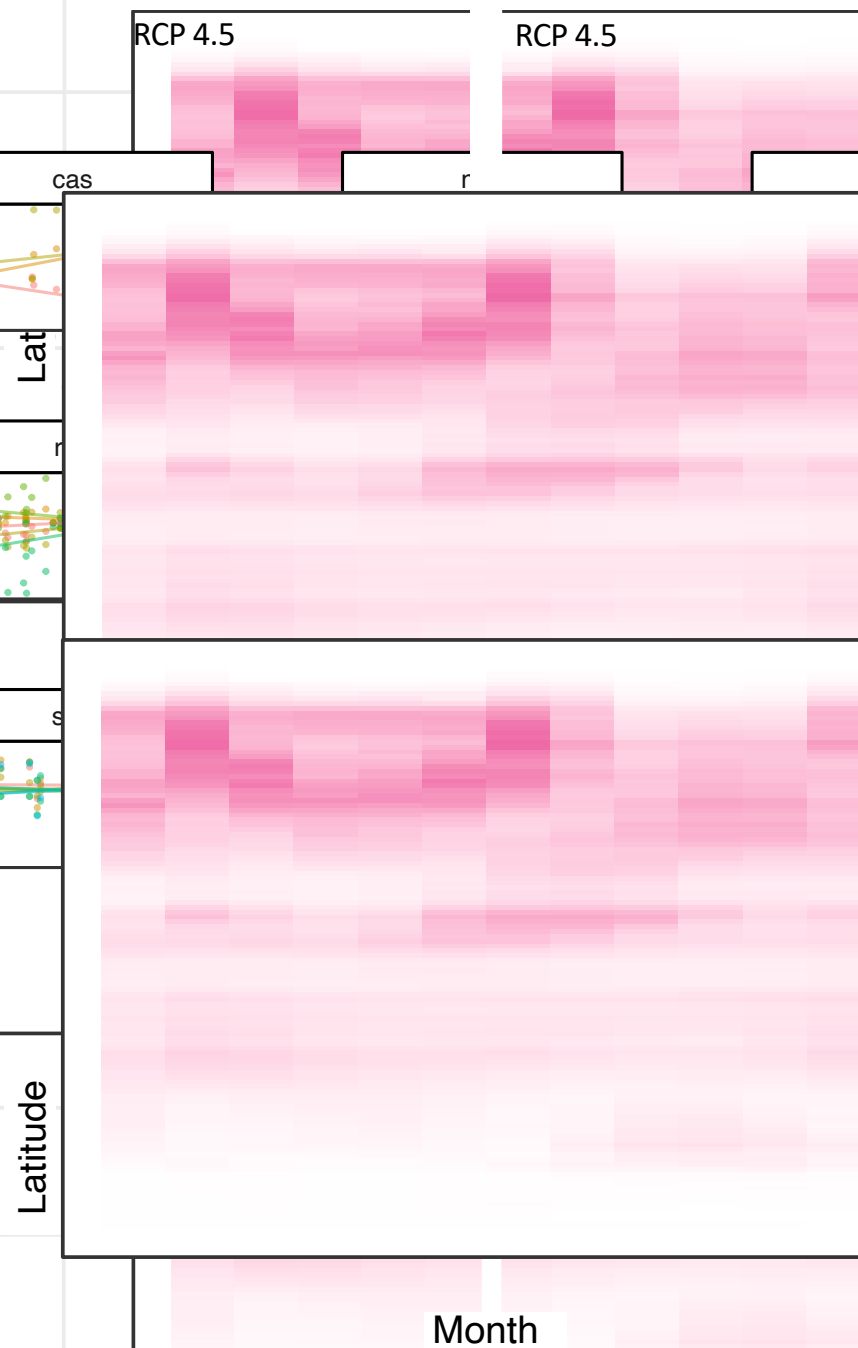

572 Fig 3. Impact of RCP and pathogen restriction method on change in $\mathrm{R}_{\mathrm{r}}$ and pathogen turnover. Red

573 and blue indicate increases and decreases in $\mathrm{R}_{\mathrm{r}}$, respectively. Darker pink indicates larger changes in pathogen turnover. Pathogens restricted by estimates of host distributions extracted from (a) EarthStat 
bioRxiv preprint doi: https://doi.org/10.1101/2020.04.28.066233; this version posted July 24,2021 . The copyright holder for this preprint (which was not certified by peer review) is the author/funder. All rights reserved. No reuse allowed without permission.

Chaloner et al.

Crop pathogens and climate change

and (b) MIRCA2000. Crop calendars only considered in MIRCA2000. Fewer pathogens included in

(b) due to fewer host distributions available. Data aggregated to $1^{\circ}$ resolution for plotting.
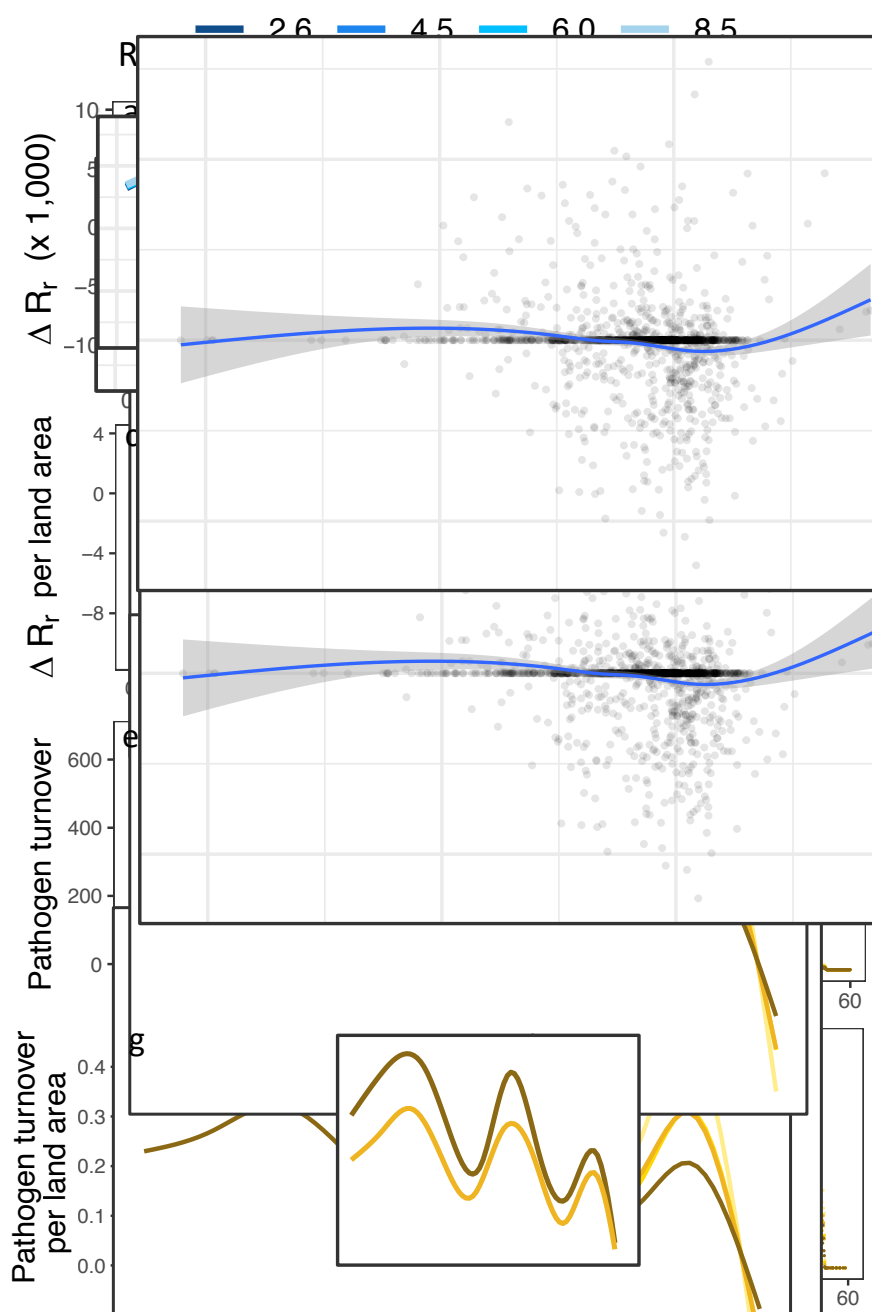

Absolute latitude

578 Fig. 4. Impact of RCP on average change of $\mathrm{R}_{\mathrm{r}}$ and pathogen turnover across all months. (a, c, e, g)

579 Northern hemisphere. (b, d, f, h) Southern Hemisphere. Pathogens restricted by estimates of host

580 distributions extracted from EarthStat. Land area refers to total land area, not crop area. 

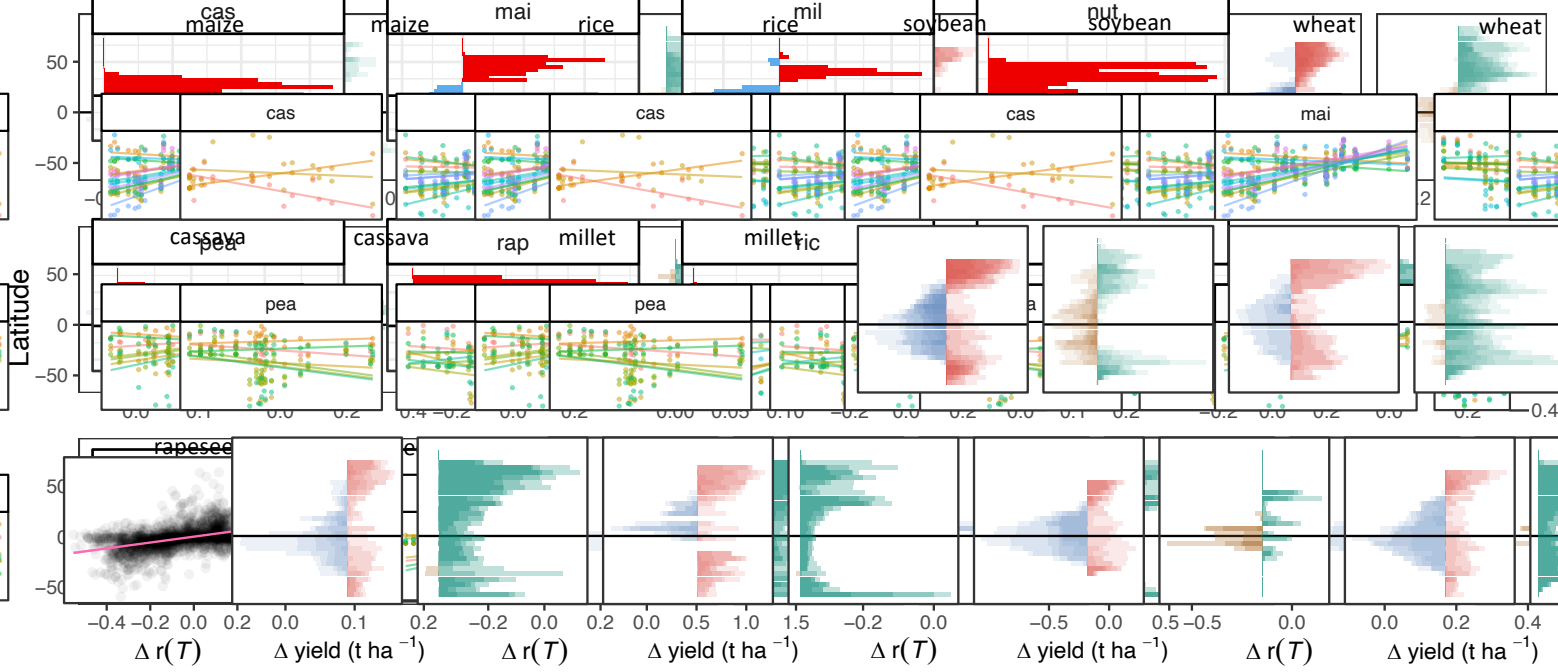

582 Fig 5. Changes in crop yield and $\mathrm{r}(T)$ under RCP 6.0 by latitude. Crops are (mai) maize, (ric) rice,

583 (soy) soybean, (whe) wheat, (cas) cassava, (mil) millet, (nut) peanut, (pea) pea, (rap) rapeseed, (sgb)

584 sugar beet, (sug) sugar cane, and (sun) sunflower. Red and blue indicate increases and decreases in

$585 \mathrm{r}(T)$, respectively. Green and brown indicate increases and decreases in crop yield, respectively, under

586 no irrigation scenario. Colour saturation indicates numbers of pathogens or number of crop- and

587 climate models. Pathogens restricted by estimates of host distributions extracted from MIRCA2000.

588 Data aggregated to $5^{\circ}$ for plotting. 